Geografia e Ordenamento do Território, Revista Electrónica

Centro de Estudos de Geografia e Ordenamento do Território

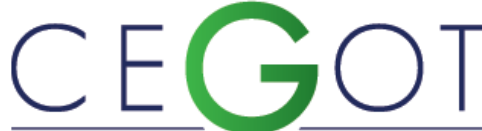

Centro de Estudos de Geografia e Ordenamento do Território http://cegot.org

ISSN :2182-1267

Veneza, A.

CEGOT

anamveneza@hotmail.com

\title{
Sistemas e Culturas de Planeamento: fatores e dinâmicas de mudança
}

Referência: Veneza, A. (2013). Sistemas e Culturas de Planeamento: fatores e dinâmicas de mudança. Revista de Geografia e Ordenamento do Território, n. 3 (Junho). Centro de Estudos de Geografia e Ordenamento do Território. Pág. 249 a 273.

\section{Resumo}

Diversidade e convergência, permanência e mudança traduzem as tendências contraditórias que caracterizam a evolução dos sistemas de planeamento espacial. A internalização da dimensão cultural pela teoria do planeamento veio permitir identificar "as relações entre valores culturais, regras, atitudes e comportamentos" prevalecentes numa sociedade e as práticas de planeamento espacial, bem como perceber o modo como estas se ajustam sob o efeito da globalização e da europeização das políticas. Os processos de mudança são desiguais, podendo coexistir, num mesmo território, vários tipos/graus de mudança, em resultado do jogo político entre as forças de inovação e as forças de persistência, dando origem a sistemas de planeamento híbridos onde, muitas vezes, a inovação é cooptada pela tradição. 
Palavras-Chave: Sistemas de planeamento, culturas de território, culturas de ordenamento do território, dinâmicas de transformação.

\begin{abstract}
Diversity and convergence, permanency and change can translate the contradictory tendencies characterizing the spatial planning systems evolution. The planning theory internalization of the cultural dimension has allowed to identify the society prevailing "relations between cultural values, rules, attitudes and behaviours" and spatial planning practices, as well as to understand the way they both adjust under the effect of globalization and policies europeanization. The changing processes are not equal and, in the same territory, several types/degrees of change can coexist, resulting from the political game between innovation and persistency forces, giving birth to hybrid spatial planning systems where, very often, innovation is co-opted by tradition.
\end{abstract}

Keywords: Planning systems, planning cultures, territorial cultures, transformation dynamics.

\title{
1. Introdução
}

$\mathrm{Na}$ literatura contemporânea sobre a teoria do planeamento deparamo-nos com frequência com os conceitos de "Spatial Turn" e de "Cultural Turn". Estes conceitos correspondem a importantes viragens conceptuais que, embora com temporalidades diferentes, se seguem a um outro marco importante que se poderá designar como o “Governance Turn" dos anos 80 do século passado. Com efeito, desde aquela época que a teoria e a prática do planeamento têm estado sujeitas a grandes pressões e a permanentes ajustamentos. Em primeiro lugar, o estilhaçamento do estado e a fragmentação da sociedade ativaram novas formas de ação pública. Em segundo lugar, a globalização económica deu relevo ao capital territorial como um ativo determinante na competição global dos territórios e colocou na agenda as questões de justiça social, tendo, finalmente, o processo de integração europeia posto em evidência a relevância 
da dimensão cultural no condicionamento dos processos de convergência dos sistemas e culturas de planeamento (Healey, 2006).

Estas viragens conceptuais refletem a incorporação pela teoria do planeamento dos mais recentes desenvolvimentos verificados nas ciências sociais em geral e, em particular, na geografia, na economia regional, na teoria das organizações e da gestão, na ciência política, etc., e têm contribuído para a construção de novas visões do planeamento - liberais, pós-modernas e neo-modernas - como resposta à crise do modelo técnico - racional moderno (Ferrão, 2010, 2011).

Esta evolução não é, porém, linear (Healey, 2006). Encontramo-nos num "período de crise e de transição" caracterizado por uma tensão constante entre os efeitos negativos da desregulação liberal, sobretudo efeitos ambientais e desigualdades sócioespaciais, o híper-individualismo pós-moderno e a inércia dos sistemas de planeamento perante um mundo em rápida metamorfose (Healey, 2006; Ferrão, 2010).

De facto, a teoria e prática de planeamento têm sido muito resistentes à contemporaneidade, ou seja: "The planning traditions itself has been 'trapped' inside a modernist instrumental rationalism for many years" (Healey, 2006:7) tendo ignorado até muito recentemente as novas concepções de espaço, Spatial Turn, a dimensão cultural das políticas públicas, Cultural Turn, ao contrário dos temas associados às questões da governança, que têm sido largamente debatidos.

Para um país como Portugal onde não há uma produção técnica - científica extensa, contínua e estabilizada sobre o ordenamento do território, os recentes trabalhos de Ferrão $(2010,2011)$ colocam-nos de súbito no cerne da reflexão científica mais actual em torno da teoria do planeamento, nas suas várias dimensões. Assim, na sua aparente simplicidade, o último livro de Ferrão (2011) transporta-nos para um novo paradigma, cuja compreensão exige múltiplas descodificações.

Aquela a que se propõe este texto dirige-se à internalização pelo Ordenamento do Território dos conceitos operacionais relativos à respetiva dimensão cultural, nomeadamente os conceitos de cultura de ordenamento do território e cultura de território (Ferrão, 2011), e à sua importância para a compreensão das "relações entre 
valores culturais, regras, atitudes e comportamentos" prevalecentes numa sociedade e as práticas de planeamento espacial, bem como perceber o modo e as dinâmicas de evolução dos sistemas e culturas de planeamento onde as relações de forças entre os diferentes atores políticos e sociais desempenham um papel decisivo.

\section{Sistemas e culturas de planeamento espacial - conceitos complexos e difusos}

As expressões "sistemas de planeamento" e "culturas de planeamento"1 são utilizadas frequentemente de forma aleatória na descrição e comparação de diferentes práticas de planeamento espacial. Trata-se, com efeito, de termos cuja conceptualização é complexa e difusa (Gullestrup, Fürst, 2009), tanto mais que têm como suporte outros conceitos, "Planeamento" e "Cultura", que são eles próprios "subtis e complexos" (Knieling et al., 2009c:311).

O conceito de "sistemas de planeamento" tem sido normalmente utilizado para designar o conjunto das estruturas político - administrativas e dos instrumentos de enquadramento e suporte das práticas de planeamento espacial, cuja configuração e natureza são, de facto, muito dependentes das tradições legais e administrativas de um país, muitas vezes assimiladas ao conceito de "planning traditions" e, portanto, correspondendo a realidades muito díspares.

Se, no entanto, desde a década de 90 , do século passado, e pelo menos na Europa, os sistemas de planeamento espacial, deste ponto de vista, têm sido objeto aturado de estudos e, nomeadamente, de estudos comparativos, a utilização do conceito de

\footnotetext{
${ }^{1}$ Por simplicidade, utilizar-se-ão, ao longo do texto, os termos de planeamento espacial ou de planeamento, tal como é cada vez mais comum na literatura europeia da especialidade. Trata-se de um conceito aparentemente neutro que permite abranger os significados que esta política pública assume em cada país, por um lado. Por outro lado, traduz o sentido comum da evolução dos respetivos sistemas e culturas, como veremos. No contexto específico de Portugal, no entanto, fará mais sentido falar em sistemas e culturas de ordenamento do território, nos termos colocados por Ferrão (2011:26ss) o qual se debruça sobre "a relação complexa e ambígua entre as expressões "planeamento" e "ordenamento do território".
} 
cultura de planeamento como conceito analítico é relativamente recente ${ }^{2}$ (Friedmann, 2005) e, portanto, pouco estabilizado (Fürst, 2009).

A internalização da dimensão cultural pela teoria do planeamento corresponde a uma nova abordagem resultante da necessidade de compreender como é que os contextos nacionais resistem ao poder homogeneizador das dinâmicas da globalização e de internacionalização das economias, das empresas, do conhecimento e da informação, bem como, ao nível europeu, da necessidade de perceber os resultados diferenciados da "Europeização do Planeamento" e das políticas de cooperação territorial.

\section{Sistemas de Planeamento - Diversidade e Convergência, Permanência e Mudança}

O estudo comparativo dos sistemas e culturas de ordenamento do território, nomeadamente, à escala europeia, tem colocado em evidência dois aspetos, aparentemente, contraditórios: a diversidade dos sistemas e culturas de planeamento, por um lado, e a tendência de convergência destes, por outro 3 .

A emergência do conceito de planeamento espacial no discurso europeu, embora não haja consenso sobre a sua definição, exprime esta evolução convergente das práticas

\footnotetext{
2 Segundo Sanyal (2005), a emergência da dimensão cultural na teoria do planeamento surge em dois momentos, no final dos anos 60 do século passado, com a primeira crise do paradigma racional compreensivo, dominante após a segunda Grande Guerra, na sequência da afirmação das culturais locais e, num segundo momento, nos anos 80 , quando os movimentos neoliberais puseram em causa o papel e as funções do estado, pondo em evidência a fragilização e a mudança na natureza do planeamento.

${ }^{3}$ Trabalhos comparativos à escala mundial têm debatido este mesmo tema (Friedmann, 2005; Sanyal, 2005).
} 
que desafiam a tradicional "missão do planeamento", o uso e transformação do solo mediante a utilização de instrumentos de comando e controlo (Böhme, 2008: 225) ${ }^{4}$.

Ferrão (2011) sintetiza as inovações que o conceito de "spatial planning" transporta em contraponto ao conceito de "land use planning" e que expressam o sentido generalizado da mudança dos sistemas e culturas de planeamento a nível europeu: mais territorialização, maior abrangência e integração das políticas setoriais, prospetiva, estratégia e participação.

Esta evolução dos sistemas de planeamento, na Europa, de acordo com Ferrão (2011), é o produto conjugado do "Efeito Mundo" (globalização do conhecimento científico e técnico, dos modelos políticos, societais e económicos) $)^{5}$ e do "Efeito Europa" (europeização das políticas nacionais ${ }^{6}$, traduzindo-se na convergência parcial dos sistemas de planeamento e das culturas de planeamento (Nadin, 2008; Ferrão, 2011). Porém, esta convergência, como vimos, não apaga a diversidade destes, o que torna óbvio "que a diversidade cultural tem uma componente espacial (...) que se traduz em diferentes significados e entendimentos do território, do planeamento espacial e dos seus objectivos, bem como em distintos sistemas de planeamento, estratégias e instrumentos"(Knieling et al., 2009: 301). Aliás, se a resposta aos diversos estímulos externos é diferenciada, os processos internos de mudança não são, de igual modo, homogéneos nem lineares (Shaw, 2006; Waterhout, 2009; Ferrão, 2011), pois as dinâmicas de transformação coexistem/conflituam com a resiliência dos sistemas e das culturas de ordenamento do território, daí resultando sistemas e culturas híbridos (Sanyal, 2005: 15).

\footnotetext{
${ }^{4}$ Um dos sintomas deste processo de convergência é o esforço crescente das comunidades técnicocientíficas em consensualizarem conceitos e/ou em encontrarem correspondências entre os conceitos utilizados nos diversos países (CEMAT, 2011), aprofundando o processo de integração discursiva.

${ }^{5}$ Sobre este assunto ver igualmente Friedmann (2005).

6 o conceito de "europeização" tem diversas aceções, sendo a que é atualmente mais utilizada (Olsen,2002, citado por Böhme, 2008) diz respeito à influência exercida "por um largo espetro de políticas comunitárias sobre o desenvolvimento e o planeamento nacional, regional e local" (Böhme,2008:233).
} 
A propósito do processo de europeização do planeamento espacial, Böhme (2008: 245) afirma que "este conduzirá a uma maior confluência entre o planeamento e os sistemas de planeamento na Europa, mas não à uniformização, tal como os resultados dos processos de Europeização refletem a heterogeneidade da Europa em termos de estruturas de governança e de governo, bem como a sua diversidade espacial". No mesmo sentido, Fürst (2009:31) chama a atenção para a "lentidão dos processos de mudança, freados por elevados "custos de transação" que serão tanto mais elevados quanto mais maduros forem os sistemas de planeamento", colocando com isso em causa a possibilidade efetiva dos sistemas e culturas de planeamento convergirem.

Por sua vez, Nadin et al. (2008: 40) são mais otimistas ao afirmarem que as "análises comparativas dos sistemas de planeamento espacial sugerem que a contínua adaptação conduz à convergência geral. Algumas mudanças incidem sobre aspectos particulares dos sistemas institucionais e legais, outras refletem uma mais geral transformação dos 'estilos de planeamento' no sentido, por exemplo, de uma maior coordenação de políticas"7 .

Conclui-se, portanto, que a convergência dos sistemas e culturas de planeamento não significa uniformização/homogeneização destes, mas apenas o reforço de elementos e tendências comuns, particularmente daqueles que têm merecido grande atenção no debate europeu, como sejam, entre outras, a integração e coordenação entre várias políticas setoriais e as novas formas de relacionamento e de comunicação entre o estado e a sociedade civil (Motte,1997).

Neste sentido, há autores que colocam a questão de não estarmos perante um processo de convergência mas, sim, perante uma nova convergência, pois os sistemas e culturas de planeamento do pós-guerra partilhariam igualmente características semelhantes, sendo por isso, catalogados como "modernos".

\footnotetext{
7 Friedmann (2005:228), pelo contrário, chama a atenção para o facto de que para além da força homogeneizadora das trocas globais "as práticas de planeamento têm ainda que responder perante as condições específicas em que operam, conformarem-se com a cultura política dominante, acomodaremse ao quadro institucional vigente, adaptarem-se às limitações dos recursos disponíveis para o desenvolvimento local e lutarem contra as tradições e interesses instalados"
} 


\section{A contextualização "difusa" dos sistemas de planeamento - a emergência/ausência da dimensão cultural}

Os resultados diferenciados ${ }^{8}$ dos processos de aprendizagem inerentes à cooperação territorial europeia, bem como a procura de denominadores comuns na evolução dos vários sistemas de planeamento europeus, colocaram em cima da mesa a necessidade de enquadrar a forma e o funcionamento dos sistemas de planeamento (Nadin et al., 2008).

Com este propósito, estes autores não só exploram a relação entre "sistemas de planeamento" e o seu "contexto", como identificam os fatores de mudança que os fazem evoluir. Ao analisarem como é que os sistemas de planeamento se adaptam (reagem) àqueles, identificam os elementos comuns das transformações operadas e que na sua perspetiva, como vimos, conduzem inegavelmente à respetiva convergência, embora reconheçam existir, em geral, resistência à mudança. Os autores definem "contexto" como "o modelo social ou modelo de sociedade prevalecente", ou seja, " o conjunto de valores sociais e culturais que estão subjacentes às políticas", mais concretamente, "a diversidade de valores e práticas que moldam as relações entre o estado, o mercado e os cidadãos" (Nadin et al., 2008: 35). Com recurso a estudos comparativos baseados em tipos ideais de "modelos de sociedade" e de "sistemas de planeamento", estabelecem o grau de correspondência entre eles.

Concluem que, em geral, existe consonância entre modelos de sociedade e sistemas de planeamento, o que decorre do facto de os sistemas de planeamento serem "a expressão de alguns valores fundamentais relativamente aos objectivos legítimos e às orientações do governo, ao uso do solo e aos direitos dos cidadãos" (Nadin et al., 2008: 43). Em consequência, os sistemas de planeamento refletem as mudanças de valores resultantes da evolução dos modelos sociais, nomeadamente nos anos 80 e 90,

\footnotetext{
8 Diferentes percepções e significados do espaço, bem como diferentes entendimentos do planeamento, dos sistemas de planeamento e dos processos afectam a cooperação territorial europeia (Knieling et al., 2009: xxvii).
} 
em resultado das pressões exercidas sobre o estado social. Concluem, por outro lado, que em consequência da "exposição a fatores externos comuns, tais como, a cooperação e competição económicas globais, os acordos internacionais e a integração europeias", e, sobretudo, devido à "cooperação extensiva entre planeadores através das fronteiras nacionais e internacionais que conduziram a uma vasta troca de ideias e de práticas", que sistemas de planeamento muito diferentes, correspondendo a contextos também bastante diferentes, evoluem de forma semelhante (Nadin et al., 2008:40), como será o caso da Holanda e do Reino Unido.

Por outras palavras, evidenciam "a importância dos fatores externos na evolução dos sistemas de planeamento, podendo a sua ação sobrepor-se à influência dos respectivos contextos" (Nadin et al., 2008:35) ${ }^{9}$. Segundo os autores, estas mudanças, que nalguns casos se têm traduzido pela implementação de reformas nos sistemas de planeamento nacionais podem ser precursoras de mudanças mais vastas nos respetivos modelos sociais.

Porém, se se atentar nos conceitos de Sistemas de Planeamento Espacial ou de Cultura de Planeamento que utilizam, verifica-se que os autores definem o primeiro como "o conjunto de soluções de governança territorial que procuram moldar os padrões de desenvolvimento espacial em lugares particulares" ${ }^{10}$ (Nadin, 2008 et al.: 35) e que o conceito de cultura de planeamento é assimilável ao conceito de tradições de planeamento, legais ou outras. Ou seja, a análise que fazem dos sistemas e culturas de planeamento está ainda muito condicionada por uma análise institucional e formal (Fürst, 2009), o que decorre aliás da natureza dos estudos comparativos em que se baseiam para estabelecer as tipologias de sistemas e tradições de planeamento.

De acordo com Fürst (2009), o entendimento restrito destes dois conceitos deve-se ao caráter limitado e à parcialidade de grande parte dos estudos comparativos que foram

\footnotetext{
9 Nesta linha, Ferrão (2011) considera que a Europeização da política de Ordenamento do Território poderá ser uma oportunidade para, em Portugal, amadurecer e legitimar a política pública de Ordenamento do Território.

${ }^{10}$ Ferrão (2011: 34) adota a definição mais ampla de Waterhout, Mourato e Böhme (2009: 239); “um sistema de ordenamento do território] é um conjunto de leis e regulamentos, configurações administrativas e organizacionais bem como discursos e [instrumentos de] política."
} 
sendo sucessivamente dominados por agendas específicas, nomeadamente, pelas consequências do Esquema de Desenvolvimento do Espaço Europeu para os sistemas de planeamento nacionais, pela importância do planeamento estratégico para a competitividade dos territórios, pelas novas formas de governação, e pelos desafios do desenvolvimento sustentável.

Esta limitação teve como consequências que os "comparative studies were closely related to the institutional side (organizative, plans, formal procedures) - while the planning processes (problem solving, patterns of planning behavior, weighing competing demands, etc.) hardly received much attention" (Fürst, 2009: 28), não captando assim a sua apropriação pelos diversos atores, ou seja, "on how the actors make use of them or how beneficial they consider informal negotiating procedures or disregard institutional procedures or even illegal actions" (Fürst, 2009: 28).

Por outro lado, estas análises não são análises dinâmicas, pois são omissas no que respeita às interações (feedback) entre as experiências dos planeadores (micro level) e o respectivo contexto institucional e social (macro level), (Knieling et al., 2009: 48).

Se Nadin et al. (2008) dão passos importantes no aprofundamento analítico da contextualização dos sistemas de planeamento, e apesar de a dimensão cultural estar implícita (Fürst,2009: 28), é ainda muito tributária da opinião de Knieling et al.(2009: 43) "A teoria do planeamento ao dar ênfase apenas aos sistemas e estilos de planeamento, etc., não teve em devida consideração os princípios de cultura, em particular a expressão da diversidade e das várias diferenças, nas circunstâncias históricas, ambientais e sociais, etc., de um determinado lugar, comunidade ou cultura".

\section{A componente espacial da diversidade cultural}

A centralidade que o espaço e o território assumem nos documentos de política europeia, em resposta aos desafios colocados pela globalização económica e pela integração e cooperação europeias, o "spatial turn", tem como suporte um novo conceito de "espaço", o qual já não é considerado como um mero suporte neutral das 
atividades económicas e sociais, "o espaço contentor"11, mas sim como uma construção social, resultante da vivência de uma comunidade numa determinada área - o território - na qual a cultura e as influências culturais assumem um papel decisivo" (Knieling et al., 2009: xxiii).

As características do contexto cultural do planeamento espacial e do desenvolvimento do território resultam da conjugação de um vasto conjunto de variáveis que inclui "singularidades históricas, atitudes, crenças e valores, tradições políticas, conceitos de justiça, representações sobre as tarefas de planeamento e sobre as competências e, finalmente, de estruturas de governança que assumem diferentes contornos e combinações num determinado momento "( Knieling et al., 2009a: xxiv), pelo que a "cultura de planeamento" vai muito para além das características das estruturas, dos instrumentos e dos procedimentos.

Knieling et al., (2009b: 43) identificam os fatores (figura 1) que enquadram e condicionam as culturas de planeamento, assumindo que mesmo as "political, legal and administrative traditions" são contextualizáveis no tempo e no espaço, ou seja, que são afetadas pelas agendas transnacionais, nacionais, regionais e locais, bem como pelas "societal traditions, values, attitudes and contemporary societal movements or changes" ${ }^{12}$.

É dando conta da riqueza multidimensional do conceito de cultura de planeamento que Vettoreto a define, definição esta adotada por Ferrão $(2011: 36)^{13}$, como “A planning culture is not only a professional culture (or ideology), but the way in which, in some historical moments, a (situated - national, regional or urban) society has institutionalized planning practices and discourses, in other words, values, ways of defining problems, rules, instruments, evaluation criteria, professional/roles and

\footnotetext{
${ }^{11}$ Concepção positivista do espaço (Davoudi, 2009; Knieling et al., 2009b).

${ }^{12}$ Sobre o carácter dinâmico das culturas de planeamento ver Sanyal (2005).

13 Como veremos a seguir, este conceito desdobra-se em “ Cultura de Território" e “ Cultura de Ordenamento do Território" (Ferrão, 2011).
} 
knowledge, and relations between institutions and actors, and among state, planners, and civil society" (Vettoreto, 2009:189).

Fig.1 O enraizamento societário da cultura de planeamento (Knieling et al.,2009b:44)

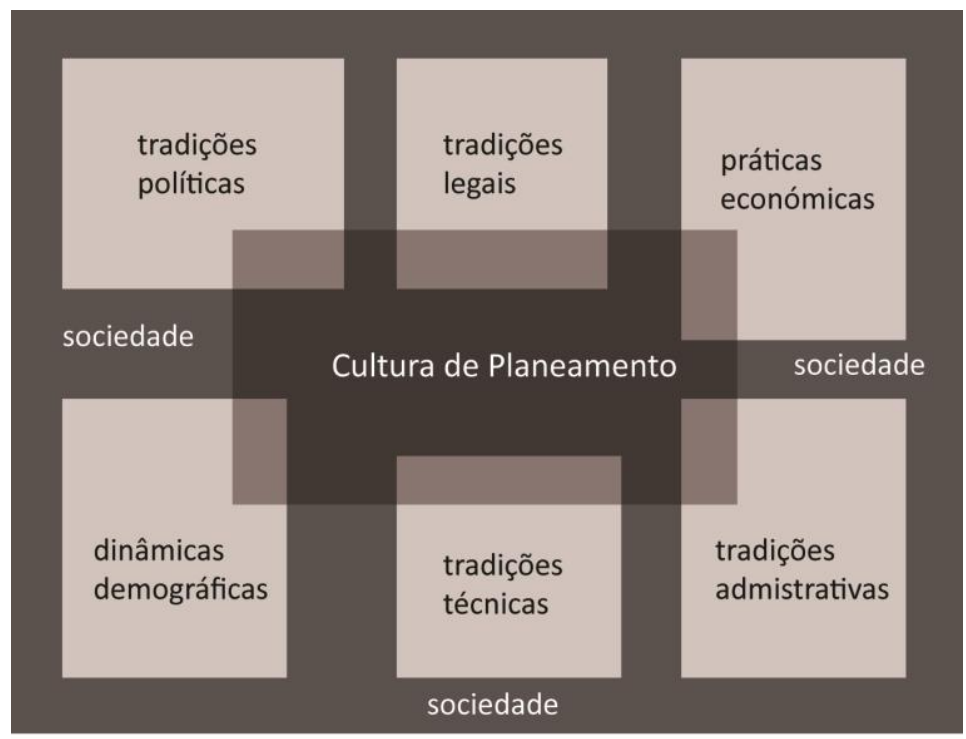

\section{Cultura e Planeamento: um modelo analítico}

Esta definição aproxima-se do conceito de cultura partilhado quer pela teoria das organizações quer pelas ciências da gestão, bem como pelos cross-cultural studies onde o paradigma cultural já prevalece. Com efeito, a incorporação pela teoria do planeamento da dimensão cultural tem-se socorrido dos instrumentos teóricos e analíticos das referidas ciências sociais, aprofundando o caminho aberto pelas teorias pós-modernas de planeamento que introduziram a dimensão social, ao teorizarem sobre a construção social do espaço e sobre as práticas de planeamento como práticas sociais (Knieling et al., 2009b).

A internalização da dimensão cultural pelas ciências das organizações e da gestão, bem como pelos estudos culturais resulta da internacionalização da economia e das 
empresas ${ }^{14}$, bem como das cidades onde o sucesso de umas e de outras depende da capacidade de gerir diferenças culturais (Knieling et al., 2009b: 49).

A partir da conjugação dos contributos dos estudos culturais, da teoria das organizações, da abordagem antropológica de Gullestrup (2009) e do modelo de Schein ${ }^{15}$, Knieling et al. (2009b: 54) propõem um modelo teórico e uma grelha conceptual que pretende identificar "as relações entre valores culturais, normas, regras, atitudes e comportamentos" e a forma como estas condicionam as práticas de planeamento espacial, e perceber, deste modo, se há especificidades culturais centrais ou fenómenos que diferenciem os modelos de planeamento e as práticas em diferentes países ou regiões (Sanyal, 2005). Procura, deste modo, construir um instrumento que "permita a análise sistemática das relações entre estruturas funcionais e mecanismos, sistemas de planeamento e estilos de planeamento, em função dos respetivos contextos culturais" (Knieling et al., 2009: 54 ss.).

Este modelo pretende analisar, assim, o impacto da dimensão cultural nas práticas de planeamento, permitindo desta forma descrever e comparar as diferentes culturas e sistemas de planeamento, indo além da análise das suas características e elementos mais visíveis a que os tradicionais estudos comparativos se limitavam, como vimos (Knieling et al., 2009c: 318).

A construção deste modelo assenta nos seguintes pressupostos teóricos:

- A definição de cultura como um conjunto partilhado de crenças, valores, atitudes, normas e regras;

- O reconhecimento da importância quer da interação entre os indivíduos, quer da sua integração coletiva;

\footnotetext{
14 "A sensibilidade cultural de uma empresa é vista como uma "vantagem competitiva" (Knieling et al., 2009b: 48).

${ }^{15}$ Outros autores vindos, sobretudo, da teoria das organizações são citados por Knieling (et al., 2009b: 48).
} 
- A distinção entre os produtos da interação de um grupo, de uma comunidade profissional que são imediatamente visíveis e identificáveis e aquilo que condiciona a sua atividade ${ }^{16}$.

O modelo estrutura-se segundo três dimensões da cultura (Schein, 2004; Gullestrup, 2009), duas das quais não são imediatamente identificáveis (crenças, tradições, valores atitudes e hábitos), mas que têm uma influência decisiva nas estruturas, nos processos e resultados do planeamento, designadas como "ambiente de planeamento" e "ambiente societário" respetivamente, e a dimensão que engloba os aspetos que são facilmente visíveis: os artefactos (ver Figura 2 e Caixa).

O segundo nível de análise, o "planning environment", menos visível do que o nível dos "planning artefacts", é aquele que permite fundamentar as especificidades e diferenças entre as estruturas espaciais e institucionais, os instrumentos, etc., de diferentes sistemas de planeamento (Knieling et al., 2009c: 307). Resulta dos valores herdados, adquiridos e partilhados pela comunidade mais diretamente ligada à atividade de planeamento, em particular, a comunidade técnico-científica. Ferrão (2011:37) dá como exemplos de "aspetos culturais contrastantes entre comunidades técnico-profissionais de distintos países os diferente papéis assumidos pelos técnicos nos processos de decisão (...) ou os critérios prevalecentes de legitimação do papel de ordenamento do território (conformidade legal ou procura de consensos, por exemplo)".

16 Nomeadamente, o que Schein (2004) designa como fenómenos invisíveis, "Perhaps the most intriguing aspect of culture as a concept is that it points out the phenomena that are below the surface, that are powerful in their impact but invisible and to a considerable degree unconscious"(citado por Knieling et al., 2009: 49). 


\section{As dimensões analíticas do modelo cultural de planeamento}

"Planning Artefacts" - os produtos dos processos de planeamento que são facilmente identificáveis e compreendidos, tais como as estruturas urbanas e os planos, ou as instituições de planeamento, etc.."

"Planning Environment " - assunções e valores que são específicos dos atores que estão envolvidos nas estruturas, nos processos e nos produtos do planeamento espacial (ex. geógrafos, urbanistas, planeadores regionais e urbanos). Esta dimensão que compreende, entre outros, os princípios, e os objetivos de planeamento (equidade, sustentabilidade, etc.), as tradições e a história do planeamento, o âmbito e a extensão do planeamento, bem como as estruturas políticas, administrativas, económicas e estruturas organizacionais."

"Societal Environment" - assunções subjacentes básicas, ou seja, as crenças, normas, perceções, pensamentos e sentimentos considerados como garantidos e que de forma inconsciente formam o quadro mental da sociedade. Traduz-se no grau de aceitação do planeamento pelos cidadãos, nos diferentes conceitos de justiça social, na relação com a natureza, etc.."

(Knieling et al., 2009b: 56ss)

(Knieling et al., 2009c: 305ss)

O terceiro nível, o "Societal Environment" é o nível mais profundo e que não é de todo visível, mas que é determinante na formação dos princípios e valores que enquadram o planeamento e constitui o pano de fundo das políticas públicas, em geral, e do planeamento em particular. Esta dimensão, de natureza antropológica, explora a multiplicidade de práticas sociais e políticas e quadros culturais que têm impacto no planeamento espacial (Knieling et al., 2009c:309) e que refletem, de facto, os impactos dos modelos socioeconómicos ou sociopolíticos no planeamento ou na relação com a natureza. É a este nível que se processa a correspondência entre o modelo social de um país e as respectivas culturas de planeamento que Nadin et al. (2008) procuraram estabelecer. 
A relação dos cidadãos, de maior ou menor confiança, com o estado, a sua organização territorial mais ou menos centralizada, e o seu funcionamento mais ou menos transparente e eficiente, a natureza positiva ou negativa das experiências históricas de planeamento, constituem vetores importantes na aceitação pela sociedade desta política pública e do recurso a mecanismos informais ou a mecanismos de exceção. Knieling et al., (2009c) destacam ainda três outros aspetos essenciais na determinação das culturas de planeamento: os valores civilizacionais relacionados com maior ou menor espírito comunitário e a relação com a natureza, ou seja, as diferentes perceções da necessidade de intervenção do estado na proteção dos valores ambientais, e a maior ou menor preocupação com a questão da "justiça social", nomeadamente com a redução das disparidades regionais e com a equidade na acessibilidade aos serviços (Ferrão, 2011). 


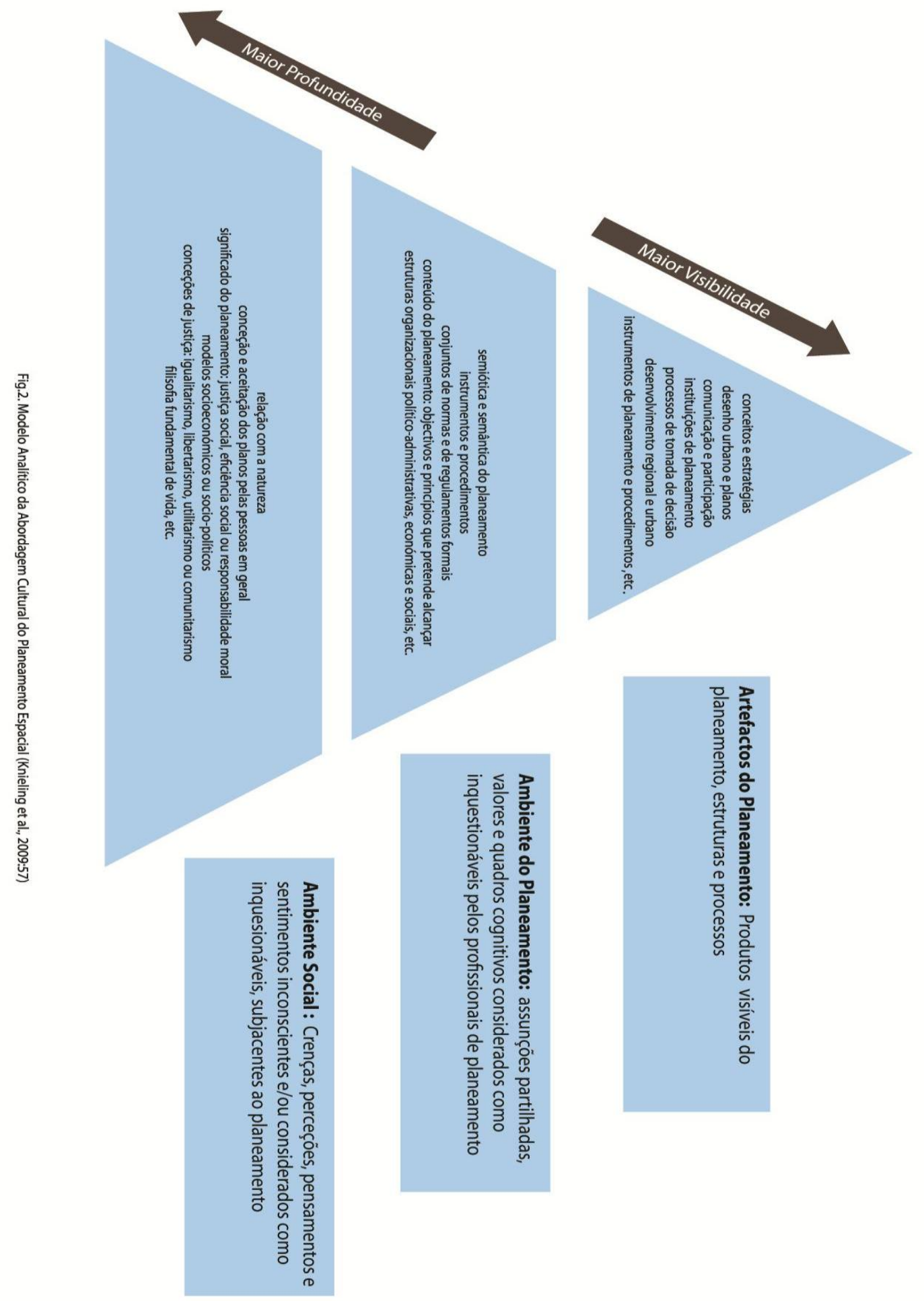




\section{Cultura de Território e Cultura de Ordenamento do Território - uma relação dinâmica}

Os conceitos de "planning environment" e de "societal environment" são, de acordo com Ferrão (2011:125), assimiláveis aos conceitos que introduz de "Culturas de Território" e de "Culturas de Ordenamento do Território", respetivamente, os quais vêm clarificar e operacionalizar o conceito de Vettoreto (2009).

A "Cultura de Território" que Ferrão (2011) designa abreviadamente, na esteira de Schein, por "Crenças", corresponde, em termos práticos, à cultura cívica de uma comunidade face ao ordenamento do território, a qual reflete as orientações políticas, ideológicas e socioculturais mais gerais dessa mesma sociedade. A "Cultura de Ordenamento do Território", abreviadamente designada por "Valores", corresponde, como vimos, ao saber adquirido e partilhado pelos membros da comunidade técnicoprofissional ${ }^{17}$.

São estes dois tipos de cultura que "moldam as orientações cognitivas individuais e de grupo, condicionando atitudes, comportamentos e práticas" (Ferrão, 2011:126). E, portanto, qualquer processo de mudança cultural ${ }^{18}$ suscetível de ocorrer no seio de uma organização, comunidade ou sociedade depende, por isso, do tipo de crenças e valores adotados e do modo como estes se alteram ao longo de processos de interação social e de aprendizagem colectiva" (Ferrão,2011:126) ${ }^{19}$.

\footnotetext{
17 De salientar que os indivíduos têm uma dupla pertença: à comunidade e à organização, ou seja, são condicionados nas suas atividades pelas crenças mentais da comunidade a que pertencem e pelos valores adquiridos na prática profissional.

${ }^{18}$ Segundo o autor " O défice de cultura de território e o peso da cultura tradicional («moderna») de ordenamento do território constituem dois obstáculos relevantes ao desenvolvimento de atitudes, competências e práticas capazes de colocar, com eficiência, responsabilidade e visão estratégica, o ordenamento do território no centro do modelo de desenvolvimento do país." (201: 117).

19 O autor considera, portanto, que qualquer processo de mudança cultural, nomeadamente em Portugal, exige um grande conhecimento dos fatores analíticos que condicionam a cultura de ordenamento do território e a cultura de território, os quais identifica (Ferrão, 2011:126ss).
} 
O modelo de Schein (1992) ${ }^{20}$ (figura 3), a que Ferrão também recorre, tal como Shaw (2006), facilita a leitura da dinâmica entre os três níveis de cultura, pondo em evidência a forte interação e mútua interdependência ${ }^{21}$. Todos estes factores se condicionam mutuamente: sistema organizacional, cultura profissional e cultura societal específicas interagem de forma reflexiva, salientando-se a dupla pertença dos profissionais à comunidade social e à comunidade técnica, ou seja, são condicionados nas suas atividades quer pelas crenças mentais da comunidade a que pertencem, quer pelos valores adquiridos na prática profissional.

De destacar ainda que os processos de mudança cultural estão estreitamente dependentes do ajustamento entre as dimensões "cultura de ordenamento do território" e "cultura de território", cujas linhas de fronteira são muito ténues e, por isso, interagem com grande intensidade.

\footnotetext{
${ }^{20}$ Como vimos, uma das fontes do modelo de Knieling et al. (2009b).

${ }^{21}$ Segundo Shaw (2006: 7), Schein (1992) define a cultura (das organizações), como o “Conjunto/Padrão de 'assunções básicas partilhadas' e 'de valores' que um grupo de pessoas adquire à medida que vai resolvendo problemas de integração interna e de adaptação externa e que funciona suficientemente bem de forma a ser considerado válido e, portanto, passível de ser ensinado a novos membros como a forma correta de apreender, pensar, e sentir em relação a esses problemas". Desta definição retiram-se 3 ideias chave:

i. os indivíduos desenvolvem práticas que se institucionalizam e cristalizam no local de trabalho e que adquirem por essa via o estatuto de atividades e "culturas profissionais";

ii. as "culturas profissionais" são dinâmicas pois estão em contínua transformação: constituem processos de aprendizagem contínua, novos estímulos, novas respostas;

iii. as culturas são "context specific", isto é, variam de lugar para lugar.
} 


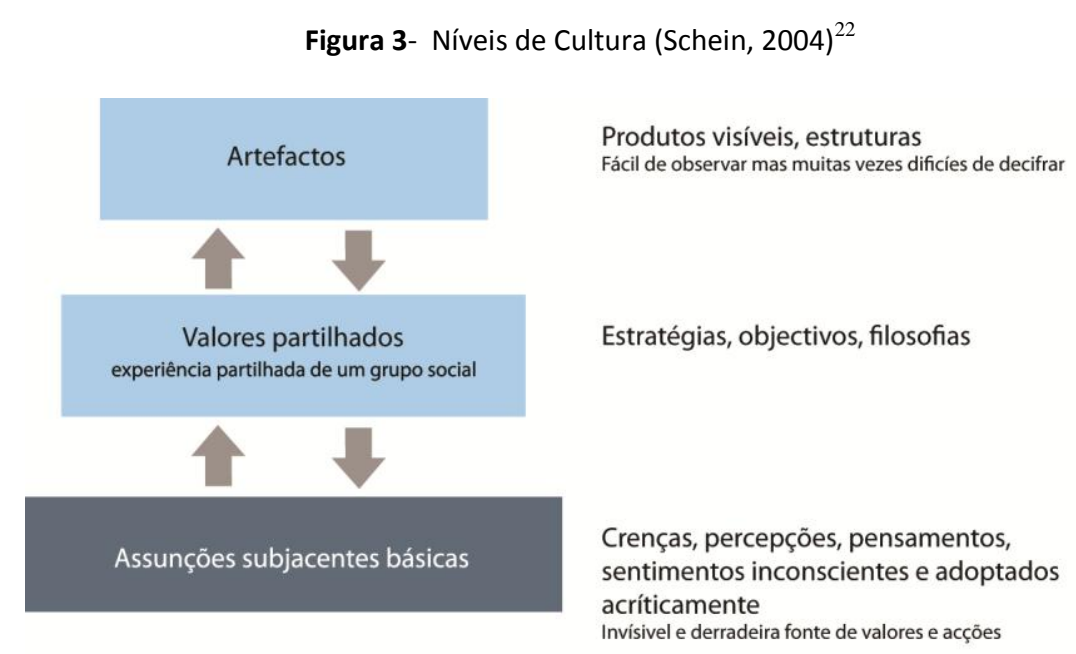

Porém, a pesada inércia das culturas de planeamento é consequência do papel determinante na forma de pensar, perceber e sentir de um grupo, das "assunções básicas subjacentes" que, pela sua natureza, raramente são debatidas e, portanto, difíceis de mudar, retardando, assim, a alteração de valores e de práticas (Shaw, 2005).

\section{Cultura de Território, Culturas e Sistemas de Ordenamento do Território - processos de mudança}

Como vimos, a cultura e, nomeadamente, a cultura de planeamento, é "manufaturada e adquirida" (Gullestrup, 2009: 4) ao longo de processos de interacção e aprendizagem social, pelo que, por natureza, não é estática. De facto, está em permanente ajustamento, em resposta a pressões induzidas por fatores internos e externos. Estas pressões e fatores podem estar na origem de mudanças de diferentes intensidade e extensão, adaptativas ou inovações radicais, mecanismos de exceção ou reformas integrais dos sistemas de planeamento, pelo que interessa perceber em que situações e de que forma os processos de mudança cultural podem acontecer, nomeadamente, quando mudam, o que os faz mudar e como mudam.

\footnotetext{
${ }^{22}$ Citado por Knieling et al. (2009:51)
} 
Shaw (2006), citando Schein, considera que as condições propícias a uma mudança cultural resultam do jogo dinâmico entre as culturas de ordenamento do território e as culturas de território, estando reunidas condições para que tal aconteça quando deixa de haver congruência entre elas. É o que se verifica quando, por exemplo, os sistemas e práticas de planeamento deixam de corresponder às expectativas sociais que sobre eles recaem, por incapacidade de resposta face a novos desafios territoriais. É o caso das pressões de mudança que incidem atualmente sobre o planeamento espacial de natureza regulamentar, pouco flexível e pouco participado, que não responde às novas exigências de governação, à complexidade dos problemas territoriais e à crescente incerteza que domina as perspetivas de desenvolvimento.

No ponto anterior deu-se conta de como os processos de mudança cultural são morosos e difíceis, em grande parte, devido à perenidade das culturas de território.

A mudança de crenças e de valores ocorre em resultado da ação conjugada de fatores externos e internos. Embora esta distinção não seja linear, os fatores externos estão associados, em geral, à exposição a outras culturas, daí a importância da globalização e europeização, e os fatores internos a factos ou a dinâmicas próprias de um país, região ou local (ex. mudanças na organização político - institucional e administrativa, mudanças de regime político, dinâmicas demográficas, desastres ambientais, etc.).

Entre estes fatores há que distinguir ainda os que induzem mudanças adaptativas sem que mudanças significativas se produzam, os «change initiave factors», e aqueles que determinam mudanças de cultura visíveis ou mesmo paradigmáticas, os «change determining factors» (Gullestrup, 2009). Estes últimos estão normalmente associados a fatores externos, com excepção da ocorrência de acontecimentos internos como mudanças de regimes políticos ou desastres naturais, etc.

Estes factores de mudança confrontam-se, em geral, com o que alguns autores designam como "forças de persistência" que traduzem a inércia dos sistemas e culturas de planeamento. Esta resistência à mudança reside nas "hard infrastructures", basicamente sistemas e estruturas administrativas, enquanto as "soft infrastructures", valores, normas e regras, são mais permeáveis à mudança.

Os processos de inovação são desiguais, quer na forma, quer entre territórios, podendo num país ou organização coexistirem vários graus ou vários tipos de 
mudança, em resultado da relação de forças e do jogo político entre as forças de inovação e as forças conservadoras, dando origem ao que já designámos por sistemas de planeamento híbridos.

A reação diferenciada das diferentes culturas de planeamento a estímulos externos depende de um conjunto de fatores dos quais se destacam:

○ " O grau de integração, que expressa a similitude e uniformidade entre os diferentes valores da cultura;

○ "O grau de homogeneidade, que expressa a amplitude e extensão do conhecimento acumulado e de objetivos partilhados;

○ Relações de poder entre culturas internas" (Gullestrup, 2009: 10).

Sanyal (2005: 20) constata que "a cultura de planeamento não é uma variável independente, mas tal como a cultura em geral de que faz parte, muda e evolui com as mudanças económicas e políticas, algumas vezes tornando-se mais democrática e participativa, outras vezes reagindo de forma totalmente diferente". Aliás, vários autores alertam para os efeitos inesperados dos processos de mudança (Shaw, 2006), os quais podem ser o resultado de vários mecanismos ${ }^{23}$ e que demonstram a importância das circunstâncias políticas e territoriais.

Davoudi et al. (2009) mostram, por exemplo, apoiando-se em vários estudos de caso, a importância que as diferentes conceções de espacialidade assumiram no processo de elaboração das estratégias espaciais, nos anos 90, sendo esse papel profundamente condicionado pelo respetivo contexto, o qual "involve complex multidimensional interactions between the institutional context of a planning episode and the creative force of agency in realizing it" (Healey, 2004). Demonstram que se os processos e os conceitos inovadores da geografia relacional adoptados na elaboração daqueles planos de natureza estratégica desempenharam um papel de "identity building" nas regiões abrangidas pelo processo de devolução no Reino Unido, as conceções de espacialidade e de lugar e as formas de representação foram profundamente afetadas, entre outros fatores, pelo jogo político associado à gestão de disparidades regionais, tendo daí

${ }^{23}$ Sobre os mecanismos que podem conduzir, em processos de mudança cultural, a resultados diferentes ou mesmo contrários aos resultados esperados, consultar Shaw (2005). 
resultado que sob uma narrativa inovadora permaneceram os velhos conceitos da geografia euclidiana.

\section{Referências bibliográficas}

Böhme, K. et al. (2008). The Europeanization of Planning. European Spatial Research and Planning. A. Faludi (Eds). Cambridge (MA), Lincoln Institute of Land Policy:225-248. CEMAT (2011), Glossário do Desenvolvimento Territorial.

http://www.dgotdu.pt/filedownload.aspx?schema=ec7b8803-b0f2-4404-b003-

8fb407da00ca\&channel=C4193EB3-3FA7-4C98-B8CA-

D6B9F5602448\&content_id=1CE61C8D-5E46-494B-BD7D-

4DDB21582ABB\&field=file_src\&lang=pt\&ver=1

Davoudi, S. et al. (2009). Conceptions of Space and Place in Strategic Spatial Planning. London. Routledge, 282p.

Ferrão, J. (2010). Território e Políticas Públicas num Período de Transição Radical. Porto: FLUP, policopiado

Ferrão, J. (2011). O Ordenamento do Território como Política Pública, Lisboa. FCG, $146 \mathrm{p}$.

Friedmann, J. (2005). "Globalization and the Emerging Culture of Planning." Progress in Planning 64, (3): 183-234

Fürst, D. (2009). Planning Cultures en Route to a Better Comprehension of "Planning Processes". Planning Cultures in Europe: Decoding Cultural Phenomena in Urban and Regional Planning. J. Knieling and F. Othengrafen (Eds.). Farnham and Burlington, Ashgate: 23-38.

Gullestrup, H. (2009). Theoretical Reflections on Common European (Planning-) Cultures. Planning Cultures in Europe: Decoding Cultural Phenomena in Urban and Regional Planning. J. Knieling and F. Othengrafen (Eds.). Farnham and Burlington, Ashgate: 3-21. 
Healey, P. (2004). "The Treatment of Space and Place in the New Strategic Spatial Planning in Europe." International Journal of Urban and Regional Research 28(1): 45-67 Healey, P. (2006). Collaborative Planning: Shaping Places in Fragmented Societies, 2nd ed.,<London. Palgrave: MacMillan, 366p.

Knieling, J. et al. (2009a). Preface. Planning Cultures in Europe: Decoding Cultural Phenomena in Urban and Regional Planning. J. Knieling and F. Othengrafen (Eds.). Farnham and Burlington, Ashgate: xxiii-xxxv.

Knieling, J. et al. (2009b). En Route to a Theoretical Model for Comparative Research on Planning Cultures. Planning Cultures in Europe: Decoding Cultural Phenomena in Urban and Regional Planning. J. Knieling and F. Othengrafen (Eds.). Farnham and Burlington, Ashgate: 39-62.

Knieling, J. et al. (2009c). Planning Cultures in Europe between Convergence and Divergence: Findings, Explanations and Perspectives. Planning Cultures in Europe: Decoding Cultural Phenomena in Urban and Regional Planning. J. Knieling and F. Othengrafen (Eds.). Farnham and Burlington, Ashgate: 301-322.

Motte, A. (1997). The Institutional Relations of Plan-Making. Making Strategic Spatial Plans: Innovation in Europe. P. Healey et al. (Eds). London, UCL Press: 231-254.

Nadin, V. et al. (2008), European Spatial Planning Systems, Social Models and Learning http://www.lote.ut.ee/orb.aw/class=file/action=preview/id=950169/01_ESP_GC_requi red01.pdf

Sanyal, B. (2005). Hybrid Planning Cultures: the Search for the Global Cultural Common. Comparative Planning Cultures. Sanyal, B. (Eds.). New York and London: Routledge: 3-25.

Shaw, D. (2006). Culture Change and Planning: Literature Review- Spatial Planning in Pratice: Supporting the Reform of local Planning. London, Department for Communities and Local Government: 36p. http://www.communities.gov.uk

Stead, D. et al. (2009). Planning Cultures between Models of Society and Planning Systems. Planning Cultures in Europe: Decoding Cultural Phenomena in Urban and 
Regional Planning. J. Knieling and F. Othengrafen (Eds.). Farnham and Burlington, Ashgate: 283-300.

Vettoreto, L. (2009). Planning Cultures in Italy - Reformism, Laissez - Faire and Contemporary Trends. Planning Cultures in Europe: Decoding Cultural Phenomena in Urban and Regional Planning. J. Knieling and F. Othengrafen (Eds.). Farnham and Burlington, Ashgate: 189-204.

Waterhout B. et al. (2009). The Impact of Europeanization on Planning Cultures Planning Cultures in Europe: Decoding Cultural Phenomena in Urban and Regional Planning. J. Knieling and F. Othengrafen (Eds.). Farnham and Burlington, Ashgate: 239253. 